\title{
Hospital Employment of Physicians Does Not Improve Quality
}

The Annals of Internal Medicine posted a manuscript on-line today reporting that the growing trend of physician employment by hospitals does not improve quality (1). In 2003, approximately $29 \%$ of hospitals employed members of their physician workforce, a number that rose to $42 \%$ by 2012 . The authors conducted a retrospective cohort study of U.S. acute care hospitals between 2003 and 2012 and examined mortality rates, 30-day readmission rates, length of stay, and patient satisfaction scores for common medical conditions for 803 hospitals that switched to the employment model compared with 2085 control hospitals that did not switch. Switching hospitals were more likely to be large (11.6\% vs. $7.1 \%)$ or major teaching hospitals (7.5\% vs. $4.5 \%$ ) and less likely to be for-profit institutions ( $8.8 \%$ vs. $19.9 \%)$ (all p values $<0.001)$.

The authors used Medicare Provider Analysis and Review File (MedPAR) from 2002 to 2013 to calculate hospital-level risk-adjusted performance on mortality, readmissions, and length of stay for acute myocardial infarction, congestive heart failure, and pneumonia. Hospital Compare data from 2007 to 2013 was used to assess overall patient satisfaction. After conversion to a physician employed model, no difference was found in any of 4 primary composite quality metrics with the single exception of readmission rates for pneumonia. That decline was modest (19.3\% vs. $19.1 \%$ readmissions) and judged not likely to be clinically significant by the authors.

Recently, Baker and colleagues found that hospital employment of physicians is associated with higher spending and prices (2). This data combined with the data from the present study suggest that the trend is for higher healthcare costs without an improvement in quality. Commenting in Medscape Richard Gunderman, a well-known healthcare delivery researcher from the University of Indiana, said that those who think quality comes from increasingly larger organizations with more advanced information technology and greater standardization across the system will see these results as surprising and disappointing (3). Pointing to high levels of burnout and widespread complaints of lack of time with patients, Gunderman said less physician control over individual patient care has taken a toll. "There's no doubt that a demoralized workforce will tend to drive quality down," he said. "Many hospitals and health systems around the country are grappling with poor and, in some cases, dismal engagement scores. I think that's an indication that a lot of physicians feel that the changes taking place across healthcare are problematic."

Funding for the study was provided by the Agency for Healthcare Research and Quality. Limitations of the study was that the patients were primarily Medicare beneficiaries aged 65 years and older. Therefore, the applicability of the findings to a younger population is unknown, however, the authors doubted that after switching to an employment model, hospitals would improve care for one group and not another. 
Richard A. Robbins, MD

Editor, SWJPCC

\section{References}

1. Scott KW, Orav EJ, Cutler KM, Jha AK. Changes in hospital-physician affiliations in U.S. hospitals and their effect on quality of care. Ann Intern Med. 2016. Available at: http://annals.org/article.aspx?articleid=2552987 (accessed 9/20/16). [CrossRef]

2. Baker LC, Bundorf MK, Kessler DP. Vertical integration: hospital ownership of physician practices is associated with higher prices and spending. Health Aff (Millwood). 2014 May;33(5):756-63. [CrossRef] [PubMed]

3. Frellick M. Physician employment by hospitals does not improve quality Medscape. September 19, 2016. Available at:

http://www.medscape.com/viewarticle/868978?nlid=109338 2863\&src=wnl d ne 160920 mscpedit\&uac=9273DT\&impID=1200121\&faf=1\#vp 2 (accessed 9/20/16). 